1921. Sohby and Tewfik.- "Tarsitis due to Meibomian cysts." Bull. Ophthal. Soc., Egypt.

1923. Poulard.-Tome I, p. 514.

1925. Heckel and Beinhauer.-Arch. of Ophthal., Vol. LIV, p. 352.

"Syphilis of the eyelids." A mer. Encyclo. of Ophthal., Vol. VII, p. 5025.

"Chancre of the eyelids." Amer. Encyclo. of Ophthal., Vol. LII, p. 2003.

1926. Connell, Evan S.- "Tertiary Syphilis of Eyelid." Amer. Jl. of Ophthal., p. 608.

1926. Le Roux, H.--"Sur un cas de tarsite syphilitique." Arch. d'Ophtal., September.

1927. Vancea, P.-“La tarsite syphilitique vegetante." Arch. d'Ophtal., October.

1932. Whiting, Maurice.- "Syphilitic Tarsitis." Trans. Ophthal. Soc. U.K., Vol. LII, p. 140.

\title{
TREATMENT OF HERPETIC KERATITIS WITH VITAMIN B
}

\author{
BY \\ J. Nitzulescu and Ecaterina Triandaf \\ FROM THE OPHTHALMOLOGICAL CLINICS, SCHOOL OF MEDICINE, \\ JASSY, ROUMANIA \\ DIRECTOR: PROF. ELENA PUSCARIU
}

THE recent progress in the study of vitamins helps us to understand better the various aspects of slight or latent hypo-vitaminosis, which occur in association with the most different clinical manifestations, and positively influence their evolution.

Such cases appear to be much more frequent than was previously suspected, and their recognition becomes a question of great importance in our European countries, where the typical syndrome of avitaminosis is rarely met, and therefore the eventual manifestations of vitamin insufficiency can easily remain hidden and ignored.

This seems to be especially the case of vitamin $\mathrm{Bl}$. Its recent synthesis, and the new possibilities of preparing it in sufficient amounts have promoted numerous essays of therapeutic trials. Different authors have studied its influence in various digestive syndromes, its active intervention in the troubles of carbohydrate metabolism (diabetes), etc.

Considering the rôle of vitamin B1 in the causation and in the cure of beriberic polyneuritis, some authors, beginning with Minot, Strauss and Cobb, were lead to try its action in other nerve diseases of various aetiology.

In fact, encouraging results have already been obtained in the treatment of alcoholic polyneuritis (Strauss, Blankenhorn and Spies, 
Jolliffe and Colbert, Sciclounoff, Russel, Levi Valensi, J. Besançon and Klotz), of the neuritis of pregnancy (Theobald, Stahler), of diabetic and diphtheritic neuritis (Sciclounoff) and of the systemic degeneration of the spinal cord, associated with macrocytic anaemia (Russel, Lasch, Bergel). Scröder and Herman reported good results in the treatment of retrobulbar neuritis.

We have also had the opportunity to follow the favourable influence of vitamin B1 in a case of bilateral trigiminal neuralgia. The patient presented at some time an incipient neuro-paralytic ulcer in the left cornea, subsequent to alcohol injections in the corresponding trigeminal nerve, which had been made before the beginning of the treatment with vitamin.

Betaxin suppressed the pains on the right (unalcoholised) side, and seemed to have also a good influence on the keratitis, arresting its progress. We could not follow the patient further, but this led us to try the vitamin treatment in another nervous, corneal disease, characterised by its dreadful pains and stubborn resistance to usual treatment, herpetic keratitis. Chance enabled us to follow almost at the same time two cases, admitted to the ophthalmological clinics, and the results obtained encouraged us to publish the following observations :

(1) Olt, I., aged 16 years, entered the clinics on June 11, 1937, suffering with gonorrhoeal conjunctivitis.

History.-Gonorrhoeal urethritis lasting since six months. One week ago conjunctival congestion of the left eye, two days ago palpebral oedema and purulent discharge. On admission, the patient shows the characteristic picture of acute gonorrhoeal conjunctivitis. Bacteriological examination of the discharge was positive. The cornea appears exfoliated.

Course and treatment.- The disease yielded quickly to the treatment with $\mathrm{AgNO}_{3}$, argyrol, mercurochrome, and vaccine-therapy. (Three injections of antigonococcic vaccine $0.1,0.3$ and 0.3 c.c. given the 12, 14 and 16 of June.) All injections were followed by fever reaching $39^{\circ} \mathrm{C}$. On June 13 , the palpebral oedema was much reduced, the fibrinous membranes disappeared. On June 14, the chemosis also disappeared and the cornea became perfectly clear. On June 15 no more secretion could be seen.

After only three days, on June 18, the patient complained again of severe headache, periorbital pain and photophobia. On examination we found: R.E., the cornea shows a few vesicles spread over its surface, not staining yet with fluorescein. Left cornea showed superficial erosions, very little infiltrated, staining in places with fluorescein and giving the image of a small ramified tree branch. The sensibility of the right cornea was normal, that of the left reduced. Our diagnosis was bilateral corneal herpes.

The usual treatment, anti-neuralgic powders and urotropin, did not 
show any appreciable result. During the night the pain was intolerable, the patient could not sleep for a moment. On June 19 all anti-neuralgic treatment was given up and we began the injections with vitamin B1. The patient has received as a whole $6 \mathrm{mgr}$. of Betaxin (Bayer) i.e. on June 19, 1 mgr., on June 20, 2 mgrs., on June 21,2 mgrs., and on June 22, 1 mgr.

From the first day of treatment the pain was much reduced. The patient could sleep quietly all night and only towards morning felt again some discomfort. The local lesions underwent quick, progressive healing. On June 20, we saw: R.E., little erosions have taken the place of the vesicles, L.E., fluorescein is retained in two spots. On June 21, R.E., fluorescein no more retained. Cornea perfectly clear. L.E., fluorescein no more retained. A single spot of infiltration exists. Between June 23 to 29 this infiltration became progressively reduced in size and density. The patient left the clinics with his left cornea nearly clear. The visual acuity of the left eye which had diminished during the disease to $1 / 10$ increased to $1 / 2$ on the day of discharge from the clinics.

(2) Maria R., aged 33 years, entered the clinics on June 25, 1927. History. - Nebula on the right cornea, dating since she was three years old, and due apparently to an inflammatory affection. One month ago she complained of an intense left hemicrania with blurring of the vision and ocular congestion. Was seen in the outpatient department of our clinics for a few days and the diagnosis was keratitis herpetica of the left eye.

The treatment with yellow mercuric precipitate, continued at home for a whole month, did not bring much change. The pains have increased, she cannot sleep during the night.

On examination, R.V., $1 / 6$; L.V., $1 / 8$. Intense left hemicrania, photophobia, perikeratc congestion reaching to the limbus. On the cornea two superficial rosions, very little infiltrated, with irregular polycyclic outline. The one which is superior has the appearance of a leaf. They retain fluorescein. The sensibility of the cornea is much reduced.

Evolution and treatment.-We continued the local applications of mercuric precipitate, atropine and adrenalin. At the same time we began the injection of Betaxin. The first injection was given on June 25. The following night the patient slept well. The local pains persisted but were much reduced. On June 26 she received 2 mgrs. Betaxin, on June 27, 28 and $291 \mathrm{mgr}$. each day. The subjective amelioriation persisted and improved. The local pains and photophobia diminished gradually. On June 30 the fluorescein was no more retained. The corneal infiltration appeared to be much reduced. Vision $1 / 2$. On July 5 the vision was increased to $2 / 3$ and the infiltration had nearly disappeared.

Discussion.-Both cases suggest a favourable action of vitamin 
B1. In the first case of herpes, occurring after a gonorrhoeal ophthalmia, in connection perhaps with the fever, all the phenomena were arrested at once and recovery followed shortly. Considering the usual protracted evolution and the resistance to treatment of the disease, the actual evolution of this case seems to be quite suggestive. The second case had already a history of nearly one month, in which the ordinary therapeutic measures seemed to have little influence. The patient entered the clinics with intensive acute symptoms and again all these phenonema receded quickly simultaneous with the vitamin treatment. In both cases the disappearance of the subjective troubles has been especially impressive and quick. The patients could sleep quietly the night after the first injection when previously they had to sit up, due to their severe pains.

How should we explain this favourable influence? In the case of an ordinary alcoholic polyneuritis the authors are inclined to admit the existence of a real hypovitaminosis $\mathrm{Bl}$ due, partly to deficient diet, partly to insufficient digestive absorption. Alcoholic gastritis should impair the absorption of vitamin B1 and prepare a latent deficiency. In fact, Jolliffe has seen in alcoholic addicts that oral treatment with vitamin $\mathrm{B} 1$, is less active than injections and that the results are to a certain extent proportionate to the doses utilised.

In some instances the need for vitamin and its utilisation seems to be above the ordinary supply. The neuritis of pregnancy is thus explained by Theobald. - Various troubles in the metabolism of carbohydrates seem to increase also the need for vitamin B1. Perhaps this could be the explanation of the diabetic polyneuritis. Levy Valensi, J. Besançon, Klotz and Silberschmidt think that such metabolic troubles (perhaps accumulation of lactic or pyruvic acid) occur in any neuritis and this is the process on which the vitamin exerts its correcting influence.

To what extent can these explanations be applied to our cases? A real alimentary hypovitaminosis seems improbable to us and the absence of digestive troubles excludes an insufficient vitamin absorption. The fever, which perhaps has conditioned the appearance of herpes in the first case, lasted for too short a period to explain a real exhaustion of vitamin reserves.

We do not consider therefore the manifestations of herpes as a process of hypovitaminosis. In such cases we are inclined to attribute to the vitamin the action of a real medicament, exerting a specific influence, functional and trophic on the nerves, which can be injured by very different aetiological agents.

Wolbach has pointed out clearly this functional action of vitamin B1. Even in beri-beri the anatomical lesions of polyneuritis do not seem directly due to avitaminosis, but rather to the starvation which is associated with it. The beri-beri animal recovers functionally in a few hours after the treatment with vitamin $B$, while the lesions 
of polyneuritis last a much longer time afterwards. This spectacular recovery proves the direct influence of vitamin B1 on the activity of the nerves. We believe that the nerves injured by the localisation of the herpetic virus benefit from a supplement of vitamin B1 just as a diseased myocardium benefits from the action of digitalis.

If this was true, the number of clinical syndromes associated with nervous troubles, which could be favourably influenced by a vitamin B1 treatment, should become more numerous, leaving out any consideration of patent or latent avitaminosis.

\section{Summary}

In two cases of keratitis herpetica, one incipient and the other of a duration of a month, the parenteral treatment with vitamin B1 (Betaxin) (amounting to 6 mgrs. in each case) brought a rapid, suggestive amelioration of the pain and seemed to stop the progress of local lesions, greatly accelerating their cure. Certainly these two cases alone are insufficient for definite conclusions. We believe, however, that they represent more than a simple coincidence and encourage us to propose the treatment with vitamin B1 in cases of herpetic keratitis and generally in all painful and neurogenic affections of the cornea.

\section{BIBLIOGRAPHY,}

Berghe1.-Ein Behandlungserfolg bei funikulärer Myelose mittels vitB1 (Betaxin). Deutsch. med. Wochenschr., Vol. LXII, p. 1643, 1936.

Jolliffe and Colbert. - The aetiology of polyneuritis in the alcohol addicts. Jl. Amer. Med. Assoc., Vol. CVII, p. 642, 1936.

Lasch.-Ein Erfolgreich mit Vitamin B1 behandelter Fall von schwerer funikulärer Myelose. Münch. Med. Wochenschr., Vol. LXXXIII, p. 1930, 1936.

Levi Valensy, J. Besancon et Klotz. - Le probième pathogénique de la polynevrite alcoolique. Soc. Med. Hop., Paris, Juillet, 1936, p. 1162.

Pagniez.-La vitamine B dans le traitement des polynévrites et spécialement de la polynévrite alcoolique. Presse Méd., Vol. I, p. 417, 1937.

Russel. - The parenteral administration of Vitamin Bi in the treatment of polyneuritis and other conditions. Edinb. Med. Jl., Vol. XLIII. p. 315, 1936.

Schroder.- Ueber einige Fortschritte auf dem Gebiete der Vitaminforschung mit besonderer Berücksichtigung der klinischen Anwendung der Vitamine. Med. Klin., Vol. II, p. 1018, 1936.

Sciclounoff and Brocard.- La vitamine B1 dans le traitement des polynevrites. Schw. med. Wochenschr., Vol. LXVI, p. 985, 1936.

Silberschmidt.--Vitamin Bl und seine Bedeutung für die Physiologie und Pathologie des Stoffwechsels. Schw. med. Wochenschr., Vol. LXVI, p. 977, 1936.

Stahler.-Hypovitaminosen in der Schwangerschaft. Münch. med. Wochenschr., p. 327, 1937.

Straus, Blankenhorn and Spies.-Quoted by Pagniez.

Theobald.- Neuritis in pregnancy successfully treated with Vitamin B1. Lancet, Vol. CCXXX, p. 834, 1936.

Wolbach.- The pathologic changes resulting from vitamin deficiency. Jl. Amer. Med. Assoc., Vol. CVIII, p. 7, 1937. 